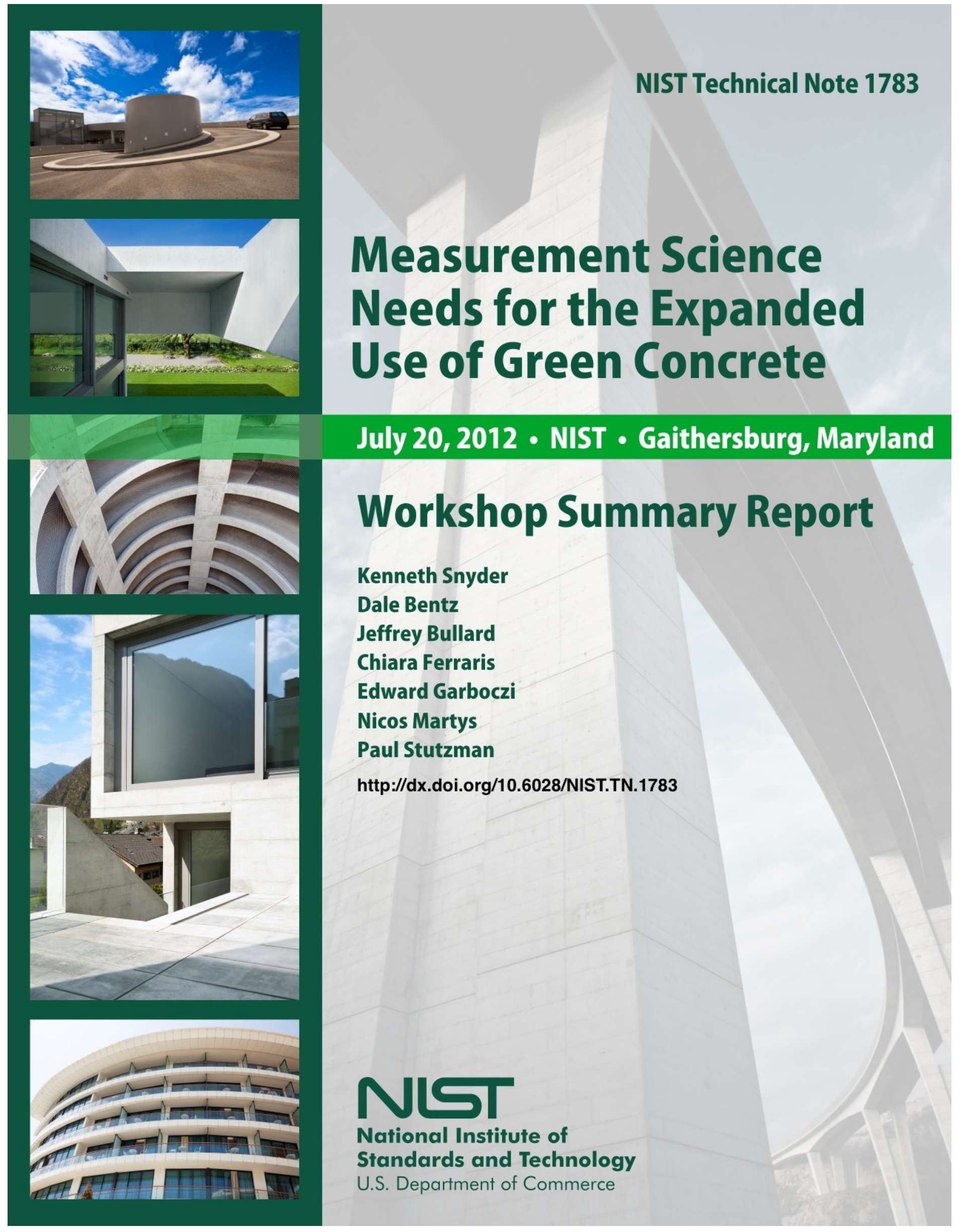


Cover Photo Credits: IStockphoto 
NIST Technical Note 1783

\title{
Measurement Science Needs for the Expanded Use of Green Concrete
}

\author{
Kenneth Snyder \\ Dale Bentz \\ Jeffrey Bullard \\ Chiara Ferraris \\ Edward Garboczi \\ Nicos Martys \\ Paul Stutzman
}

Materials and Structural Systems Division

Engineering Laboratory

http://dx.doi.org/10.6028/NIST.TN.1783

February 2013

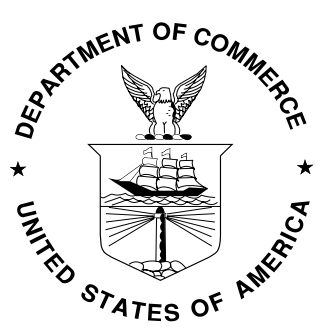

U.S. Department of Commerce

Rebecca Blank, Acting Secretary

National Institute of Standards and Technology Patrick D. Gallagher, Under Secretary of Commerce for Standards and Technology and Director 
Certain commercial entities, equipment, or materials may be identified in this document in order to describe an experimental procedure or concept adequately. Such identification is not intended to imply recommendation or endorsement by the National Institute of Standards and Technology, nor is it intended to imply that the entities, materials, or equipment are necessarily the best available for the purpose.

National Institute of Standards and Technology Technical Note 1783 Natl. Inst. Stand. Technol. Tech. Note 1783, 32 pages (February 2013) http://dx.doi.org/10.6028/NIST.TN.1783

CODEN: NTNOEF 


\section{ACKNOWLEDGMENTS}

The Inorganic Materials Group at the National Institute of Standards and Technology would like to thank everyone who contributed their time and expertise by participating in the Measurements Science Needs for the Expanded Use of Green Concrete workshop. This report is based on the presentations and discussions that took place at the workshop. Special thanks are extended to plenary speakers, listed below, and to the many expert participants, shown on the next page.

\section{Plenary Speakers}

Ryan Henkensiefken, U.S. Concrete

Marc Wanagas, U.S. Navy

This workshop and summary report were commissioned by the National Institute of Standards and Technology (NIST) Inorganic Materials Group, Materials and Structural Systems Division within the Engineering Laboratory. The workshop planning, execution, and preparation of this summary report was conducted under the direction of Kenneth Snyder, Leader of NIST Inorganic Materials Group, with significant contributions from members of the NIST Inorganic Materials Group, Energetics Incorporated, and the NIST Conference Program.

Copies of this report can be obtained by contacting Kenneth Snyder at kenneth.snyder@nist.gov.

Certain commercial entities, equipment, or materials may be identified in this document in order to describe an experimental procedure or concept adequately. Such identification is not intended to imply recommendation or endorsement by the National Institute of Standards and Technology, nor is it intended to imply that the entities, materials, or equipment are necessarily the best available for the purpose. 


\section{WORKSHOP PARTICIPANTS}

Adams, Thomas - American Coal Ash Association

Ardani, Ahmad - U.S. Department of Transportation and Federal Highway Administration

Arnold, Terry - Federal Highway Administration - Turner-Fairbank Highway Research Center

Bentz, Dale - National Institute of Standards and Technology

Blair, Bruce - Lafarge

Bumrongjaroen, Walairat - The Catholic University of America

De La Varga, Igor - Purdue University

Ferraris, Chiara - National Institute of Standards and Technology

Garboczi, Edward - National Institute of Standards and Technology

Henkensiefken, Ryan - U.S. Concrete

Juenger, Maria*- University of Texas at Austin

Keiper, Hank - The Sefa Group

Kinney, Fred - Ceratech Inc.

Koehler, Eric - Verifi

Kojundic, Tony - Silica Fume Association

Kosmatka, Steve* - Portland Cement Association

Kozikowski, Ronald - North Starr Concrete Consulting

Lane, Daniel Stephen - Virginia Department of Transportation
Livingston, Richard - University of Maryland

Lu, Yang - National Institute of Standards and Technology

Martys, Nicos - National Institute of Standards and Technology

Meininger, Richard - Federal Highway Administration - Turner-Fairbank Highway Research Center

Meyer, Christian - Columbia University

Porter, Jonathan - U.S. Department of Transportation and Federal Highway Administration

Silva, Denise* - W.R. Grace

Snyder, Kenneth - National Institute of Standards and Technology

Stutzman, Paul - National Institute of Standards and Technology

Sutter, Larry*- Michigan Technological University

Tanesi, Jussara - Global Consulting and Federal Highway Administration

Taylor, Peter*- National Concrete Pavement Technology Center

Wanagas, Marc - U.S. Navy

Weiss, Jason*- Purdue University

(* = participated via phone) 


\section{TABLE OF CONTENTS}

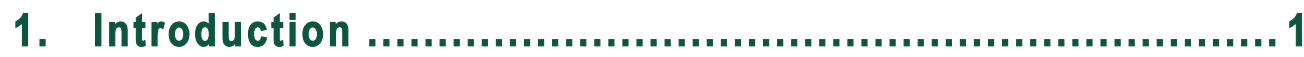

Background and Importance of Green Concrete ..........................................

Energy and Emissions from Cement Production ............................................ 2

Workshop Scope and Objectives.............................................................

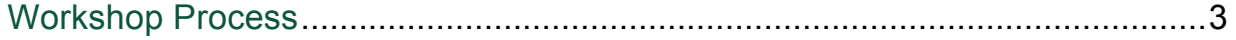

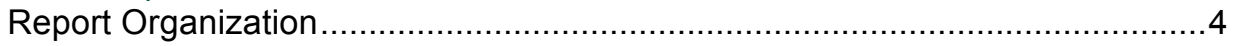

2. Characteristics of Green Concrete ............................5



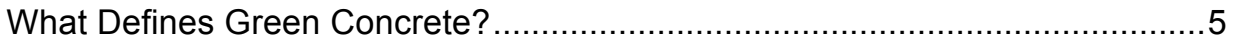

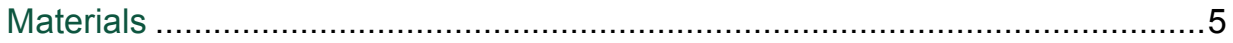

Green Manufacturing Processes and Methods .......................................... 7

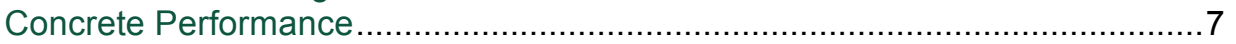

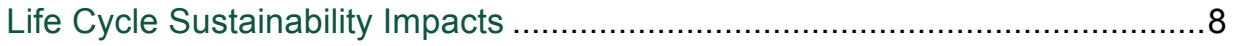

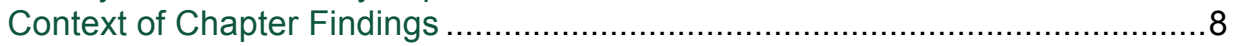

3. Technology Challenges ..................................... 9

Overview of Technology Challenges ……..................................................

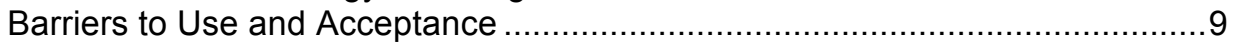



4. A Measurement Science Roadmap .......................... 25

Materials Characterization Test Methods ………...................................25

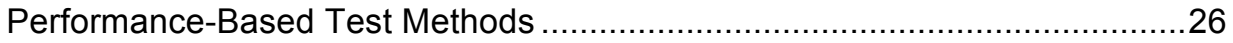

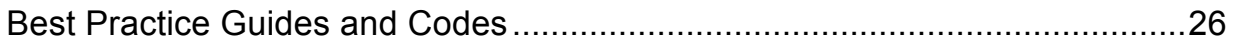

Appendix A. Successful Examples of Green Concrete........ 28

Appendix C: References ................................................ 32 


\section{INTRODUCTION}

\section{Background and Importance of Green Concrete}

Concrete materials are the most abundant manufactured materials in the world. Concrete is a desirable engineering material because of its high compressive strength, its ability to be paired with steel reinforcement to form structural elements, its ability to adapt to any form, and its relative durability compared with other construction materials. It is used in foundations, pavement, bridges, roads, dams, buildings, industrial plants, ports, parking structures, pipes, fences - virtually any engineered structure can be built using concrete.

The primary components of concrete are gravel/stone, sand, water, and portland cement. Although the portland cement constitutes only $10 \%$ to $15 \%$ of the total volume, it is the critical material system that, upon reacting with water, binds the other components together. ${ }^{1}$ Unfortunately, the production of portland cement is energy intensive and emits nearly a kilogram of carbon dioxide $\left(\mathrm{CO}_{2}\right)$ for each kilogram of cement produced. The energy intensity of portland cement production makes it the most expensive component of concrete.

There are numerous portland cement replacement materials that can be used to reduce the amount of portland cement in concrete, such as fly ash, slag, and silica fume. These supplementary industrial by-product (IBP) materials are among the most feasible means of reducing the embodied energy and associated greenhouse gas (GHG) emissions. The concrete construction industry has been using IBP materials in concrete for more than half a century. The first major breakthrough was the construction of Hungry Horse Dam in 1948, which utilized 120,000 metric tons of fly ash. Appendix A provides some examples of the successful use of these materials in concrete.

In addition to the energy and emissions benefits, a number of these materials are byproducts of an industrial process that are often destined for disposal in a landfill, and can frequently be obtained at a lower cost (on an equal volume basis) than portland cement. Therefore, the expanded use of IBP materials could also help to make concrete more cost competitive with respect to other construction materials like steel or asphalt. The replacement of a portion of the portland cement by a material like fly ash can also result in a concrete having improved performance characteristics over the corresponding plain portland cement concrete mixture. Current concrete construction practices routinely replace up to $30 \%$ or more of the portland cement with IBP materials, the most common replacement materials being fly ash and slag. 
Reducing the amount of the portland cement in the concrete mixture also creates challenges. The concrete construction industry has more than a century of experience with the successful design and construction of portland cement concrete mixtures. The properties of ordinary portland cement (OPC) concrete, especially during the construction phase and during the first few days of strength development (which can be critical for maintaining construction schedules), are fairly wellunderstood and reproducible. As more of portland cement is replaced with IBP materials the properties of the concrete change, particularly during construction and at early ages.

The primary reasons for the change in these properties are the reactivity and particle size of the IBP materials. Generally, slag is slightly less reactive than portland cement, and fly ash is less reactive than slag. As a result, setting time and strength gain can be delayed with respect to a corresponding OPC concrete mixture. Over the long-term, however, these blended systems typically develop less permeable microstructures with improved performance and durability.

The apparent lack of robustness at early ages, combined with the longer time required to achieve design strength and unfamiliarity with the unique requirements of using high-IBP concrete, have made the U.S. construction industry reluctant to freely allow arbitrary replacements of portland cement with IBP materials. This is evident in limitations on how much portland cement can be replaced or on the time of year when the use of IBP materials are allowed (i.e., due to environmental conditions).

To enable greater cement replacement by IBP, there is a strong need for better standards, guides, and tools for designing, constructing, and ensuring the performance of green concretes. These will provide the concrete industry with methods to assure that the materials will perform reliably both during construction and throughout their service life.

\section{Energy and Emissions from Cement Production}

Cement production is an energy-intensive (Watts/\$ shipment) process. Currently, the U.S. cement industry consumes more than 400 million gigajoules (GJ) annually, which is equivalent to the energy required to power more than 3 million homes each year. ${ }^{2,3}$ As noted, cement manufacturing is particularly energy intensive due to the intense heat requirements of kiln pyroprocessing, where reaction temperatures can exceed $1500{ }^{\circ} \mathrm{C}$.

Cement manufacturing contributes more than $5 \%$ of U.S. industrial $\mathrm{CO}_{2}$ emissions. ${ }^{4,5,6}$ This large contribution to industrial $\mathrm{CO}_{2}$ is the result of combustion emissions (primarily fuel combustion to achieve the high temperatures that are required during cement production) and large amounts of process emissions that are emitted during calcination. Calcination is the thermal decomposition of limestone (calcium carbonate), which is one of the primary raw materials for cement production. For each metric ton of cement produced, 0.90 to 0.95 metric tons of 
$\mathrm{CO}_{2}$ is released through the construction cycle of the resulting concrete: producing the cement clinker, grinding the cement clinker, cement shipment, concrete production and delivery, etc. ${ }^{7,8}$

U.S. cement production is expected to reach 100 million metric tons by 2016 , a production value last approached in $2006 .{ }^{9,10}$ Demand for this important building and transportation infrastructure material is expected to grow in the years to come due to population and economic growth. In a society that increasingly values greater energy efficiency and lower $\mathrm{CO}_{2}$ emissions, measurement standards and other practices that enable further deployment of green concrete will play an increasingly important role in the U.S. economy.

\section{Workshop Scope and Objectives}

The mission of the National Institute of Standards and Technology (NIST) is to promote U.S. innovation and competitiveness through measurement science, standards, and technology. To promote innovation and competitiveness in the use of novel concreting materials, NIST convened a one-day workshop to support the expanded use of green concrete throughout the concrete construction industry. The goal of the workshop was to identify and prioritize the measurement science needs for quantifying and ensuring the short- and long-term performance of green concrete - concretes having more than $30 \%$ of portland cement replaced with IBP or other substitute binder materials. The workshop solicited input from a diverse set of stakeholder experts from the construction industry, research organizations, and public sector entities; participants from the U.S. Department of Defense, state and federal Departments of Transportation, leading universities, trade associations, consultants, and industry attended the workshop.

\section{Workshop Process}

The workshop was divided between keynote talks and breakout discussion sessions. During the workshop, participants provided input on the following topics:

- Characteristics of green concrete

- Major barriers and challenges inhibiting the expanded use of green concrete

- Approaches for overcoming key barriers and challenges

Facilitated discussions on these topics during parallel breakout sessions generated a wealth of ideas. At one point in the discussions, participants were asked to prioritize the major barriers or challenges inhibiting the expanded use of green concrete. The most critical barriers identified through the prioritization process were then examined further to understand potential

Workshop Definition of Green Concrete

For purposes of the workshop, green concrete was defined as concrete containing industrial by-product or other substitute binder material in place of about $30 \%$ or more of portland cement. Chapter 2: Characteristics of Green Concrete provides additional discussion as to what constitutes green concrete. 
approaches for addressing the obstacles, including the measurement science needed.

\section{Report Organization}

The remainder of this report is organized around the topics noted above. The following sections are a combination of the input provided during the plenary sessions and discussions occurring during breakout sessions. The results presented here represent the viewpoints of the participants and stakeholder groups that attended the workshop, and are not intended to be all-inclusive of the perspectives of the concrete industry.

In addition to the report sections, appendices provide information on the successful examples of green concrete (Appendix A), acronyms used throughout the report (Appendix B), and references (Appendix C).

The information presented in this report helps provide the foundation for a comprehensive plan to ensure that measurement science keeps pace with and catalyzes technological innovation in the field of concrete construction materials. 


\section{CHARACTERISTICS OF GREEN CONCRETE}

\section{Overview}

"Green Concrete" is a term used in the concrete industry that can have many different definitions to various stakeholders. It can be defined by the type of materials used, the methods with which it was produced, the performance of the concrete, and/or the impacts due to displacing the production and use of conventional concrete. Due to these varying definitions, it was useful for the participants of this workshop to discuss what makes concrete "green," and the associated characteristics that distinguish it from other types of concrete.

\section{What Defines Green Concrete?}

The key factors that are used to identify whether concrete is considered "green" include the following:

1) Amount of portland cement replacement materials

2) Manufacturing processes and methods

3) Performance

4) Life cycle sustainability impacts

\section{Materials}

The material composition is the most transparent factor defining green concrete as distinct from other types of concrete. Concrete is typically composed of portland cement, coarse aggregate, chemical admixtures, sand, water, and supplementary cementitious materials (SCMs). Alteration from the standard concrete composition can improve the environmental, physical, and durability performance of the concrete, typically by reducing the amount of portland cement. Materials that can replace a portion of the portland cement include fly ash, silica fume, slag (iron blast furnace slag as well as other non-steel process slags), ashes from foods (such as rice husk ash), cement kiln dust, and raw or calcined natural pozzolans such as calcined clay. 
Alternative materials - or ratios of materials - for the other concrete components can also be used. Using recycled aggregate such as process clays or crushed returned concrete is a strategy for reducing embodied energy. Crushed glass in fine particle form is another alternative. The water component can be replaced with non-potable sources (gray water from sewage or wastewater treatment, sea water if the concrete has no embedded steel), if they do not contain dissolved materials that could adversely affect concrete performance (i.e., non-potable sources of mix water per ASTM C1602 and equivalent European and Australian standards). Water content can be reduced through mixture design, but cannot be totally replaced with another material. Alternative binders can include geopolymers, mono-calcium silicate, magnesium oxide, and metakaolin. An illustrative list of potential alternative materials is shown in Table 2-1.

\section{TABLE 2 1. EXAMPLES OF ALTERNATIVE MATERIALS IN GREEN CONCRETE}

Alternative Binders

- Fly ash

- Fly ash from coal-fired power plants

- At least $30 \%$ to $50 \%$ of fly ash by mass of the cementitious material is considered "green" (for purposes of this report)

- Silica fume

- Sourced from silicon alloy production by-product

- Slag from iron blast furnaces in steel production and other ferrous and nonferrous processes

- Limestone powder

- There is a $30 \%$ limestone replacement limit in Europe, and a $15 \%$ limit in Canada

- Ashes from food (e.g., rice husk ash)

- Cement kiln dust

- Chemically activated binders: geopolymers

- Raw or calcined natural pozzolans: calcined clay

Alternative Constituents

- Recycled aggregate materials

- Examples include process clays, crushed recycled or reclaimed concrete aggregate from demolition of concrete pavements or structures, crushed returned concrete (from the ready-mix truck), some mixed rubble (depending on content), and other postindustrial and post-consumer materials

- Incorporating crushed concrete can reabsorb $\mathrm{CO}_{2}$

- Reduced potable water content (via design or non-potable sources of mix water per ASTM C1602 and equivalent European and Australian standards)

Materials use strategies

- Alternative cement kiln feed materials. Using less limestone as a feed material in cement production reduces energy use and generates fewer GHGs (reduced calcination).

- Use of waste materials as alternative fuels for the cement industry

- Use of non-hazardous materials: safe to handle, store, transport

- Use of local materials (less transport fuel) 


\section{Green Manufacturing Processes and Methods}

Green manufacturing processes and methods refer to alternative or novel approaches or techniques that may be used in the production of concrete. Alternative approaches can include more efficient concrete production processes: mix design, testing, and manufacturing. Examples include using processes that create a minimum of waste, reusing waste materials as alternative fuels, and alternative methods that replace calcination or reduce the energy and emissions from the clinker production process. Examples of manufacturing and methods processes that are characteristic of green concrete are shown in Table 2-2.

\section{TABle 2 2. EXamples of Green Concrete Manufacturing Processes}

\section{AND METHODS}

Manufacturing methods

- Reducing energy use and GHG emissions from fuel combustion

- Alternative clinkers: belite cements, calcium aluminate (CA) cements.

- More-efficient concrete production, including mix design, testing

- Reduced labor requirements during construction: self-consolidating concrete

- Using greater percentages of IBP in lieu of portland cement.

Informational and policy frameworks

- Life cycle analyses (LCA) studies and associated metrics that demonstrate "greenness" of cement/concrete

- Decision-making methods for concrete evaluation and purchasing decisions that consider social, economic, and environmental factors

\section{Concrete Performance}

Despite the different materials and methods used in its formation, green concrete has performance characteristics similar to standard concrete so it can be employed for the same construction purposes. This includes having a high strength-to-mass ratio, a significant thermal efficiency/mass, and predictable long-term performance. Construction codes for concrete today are based largely on prescriptive specifications. Specifications that are performance-based, however, would allow green concrete to compete with standard concrete as long as the performance meets the buyer's requirements. The U.S. government has released specification guidelines for marine concrete (UFGS 0331 29, August 2012) that includes a protocol to assist in implementing performance-based specifications on projects. Examples of concrete performance requirements are shown in Table 2-3. 


\section{TAble 2 3. Examples of Concrete Performance ReQuirements}

- Compressive strength

- Strength-to-mass ratio

- Thermal efficiency/mass - heating/cooling of building

- Level of porosity for concrete for control of storm water (carbonation)

- Durability under certain exposure classes

- Mechanical properties (flexural strength, elastic modulus, creep)

- Transport properties (ionic diffusion coefficient, moisture transport coefficient, permeability)

- Dimensional stability (plastic, autogenous, and drying shrinkage, warping/curling)

- Resistance to chemical attack

- Intended duration of service life under field conditions, as determined from validated service life computer models

\section{Life Cycle Sustainability Impacts}

The final important characteristic of green concrete is the collective impact of its usage. Green concrete improves the three pillars of sustainability: environmental, economic, and social impacts. For environmental and economic impacts, green concrete reduces GHG emissions, uses fewer virgin materials, consumes less energy, and lasts longer (requiring fewer replacements of structures) than OPC concrete, when considering the life cycle of the product. Pervious concrete can also provide an environmental benefit by mitigating excessive storm water runoff in urban and suburban locations. An illustrative list of green concrete impacts and costs is shown in Table 2-4.

\section{TABLE 2 4. EXAMPLES OF GREEN CONCRETE IMPACTS AND COSTS}

Impacts

- Significantly reduced lifecycle environmental impact in terms of GHG emissions, water use during production, and fuel and energy usage

- Reduced energy requirements for heating and cooling of buildings

- Durability and reduced life cycle cost

- Pervious surfaces that can reduce storm water runoff

- Financial costs that are comparable to conventional options

\section{Context of Chapter Findings}

While this chapter broadly defined characteristics of green concrete, the remaining portion of this report focuses on expanding the use of green concrete within its limited definition for the purposes of the workshop; that is, focusing on the materials portion of concrete, and in particular the binder material. The working definition concentrates the focus on identifying challenges and opportunities for the specification and use of concrete mixtures having IBP or other substitute binder material replace $30 \%$ or more of the portland cement. 


\section{TECHNOLOGY CHALLENGES}

\section{Overview of Technology Challenges}

Green concrete has the potential to provide numerous benefits, including enhanced engineering performance, energy efficiency, and environmental performance. However, as with any new technology, green concrete faces challenges to its largescale acceptance and implementation. Green concrete, as defined in the previous section, is concrete that uses alternative binder materials while achieving the desired performance. Materials, performance, and other technical and non-technical factors play important roles in understanding the critical challenges faced when expanding the use of green concrete in the construction industry.

This chapter provides a prioritized set of challenges and barriers that were identified as inhibiting large-scale implementation of green concrete. Note that the manner by which these ideas were brought forward was a consequence of the number of workshop participants. To keep the group sizes optimal, the participants were divided between two groups (Group A and B), each developing ideas independently of one another. A smaller group size encourages greater participation from everyone and often yields the greatest number of different ideas. Another advantage to this approach is that ideas that were developed independently would suggest a broader consensus.

\section{Barriers to Use and Acceptance}

The barriers to the expanded use and acceptance of green concrete are broadly situated in the categories described below.

Performance specifications are integral to allowing green concrete to compete against standard concrete and other construction materials. Current prescriptive specifications often constrain acceptance to traditional concrete mixtures, thus preventing alternative materials or mixture proportions with different but otherwise acceptable processing requirements or hardened characteristics from being used. 
Before broad acceptance of these materials can occur, overly-restrictive prescriptivespecifications need to be overcome, and the performance of green concretes must be demonstrated to be either OPC-equivalent or sufficient for the intended application (which may require performance beyond that of OPC concrete).

Performance measures and test methods are needed to ensure that concrete meets the necessary short-term and long-term performance requirements. Current test methods are often not applicable to these new materials and, therefore, new or improved test methods need to be developed. In addition, models are needed that can predict the performance of the range of green concretes, as well as life cycle analyses to ensure that they will be sufficient or even better replacements for traditional concrete. The tools, data, methods, and models do not exist or are inadequate, yet they are essential enablers for achieving a greater deployment of replacement green concretes.

Property variability among IBP material types, or even among different sources of the same material, can require concrete mixture reformulations. These variations in IBP material performance make it difficult to develop IBP material specifications that would apply to a wide range of concretes. A main challenge is that green concrete's characteristics and properties vary between products and even between sources, including early strength gain and set times. For example, there may be difficulties in establishing consistent material combinations and other parameters due to variable performance attributes of the IBP materials.

Characteristics of replacement materials must be better understood. For example, concrete mixtures with larger amounts of SCMs typically have slower strength gain when compared to similar OPC concretes. If engineers testing the concrete are not aware of the inherently slower (yet ultimately sufficient) strength gain, and the actual time at which the required strength is needed, they can misinterpret the adequacy of the product.

Codes and regulations can restrict the broader deployment of green concrete technology. This covers a range of issues related to regulation, permitting, contracting, and incentives.

Contracting practices can limit the ability of constructors to readily incorporate green concrete. Contracting procedures, for example, involve multiple stakeholders who all must agree to move forward on a project, which can be difficult when new products, regulations, or specifications are introduced. Policies are also lacking to assign responsibility for the risks of using green concrete. This creates uncertainty about who will take responsibility in the event of failure.

Education and training on construction practices, performance, benefits, and technical issues related to green concrete are needed to foster and facilitate greater acceptance and implementation of replacement concretes. In general the 
construction industry is conservative and cautious in implementing new technologies and practices until reliability and performance are proven.

The complete set of barriers identified within the above categories is shown in Table 3.1. The relative importance of these barriers is denoted as high, medium, or low priority, and was determined by participants through a group voting process. Note that the barriers listed are not intended to be all-inclusive, but represent the perspectives of the participating experts. 


\section{TABLE 3 1. BARRIERS TO THE EXPANDED USE OF GREEN CONCRETE}

\section{Performance Specifications}

- Inadequacy and/or absence of performance specifications, including:

- Shortcomings of standards for coal fly ash and raw or calcined natural pozzolan for use in concrete: under ASTM C618, only Class F fly ash is specified by the UFGS as a partial replacement for portland cement

- Existing specifications that limit the increased use of SCMs

- Lack of adequate performance specifications for concrete (green or otherwise)

- Specifications often artificially limit high-volume replacement levels based on early age data and lack of confidence in then-new and relatively unknown materials

- Specifications often rely upon specific material characterization requirements that were developed for OPC concretes

- Lack of an actionable roadmap (and priorities) for the acceptance of IBPs and SCMs using characterization measurements, enabling performance-based specifications

Low - Lack of an alternative set of specifications that are based on performance

Priority - Understanding, managing, and tracking risk changes

\section{Differences in Performance}

\begin{tabular}{|c|c|}
\hline $\begin{array}{l}\text { High } \\
\text { Priority }\end{array}$ & $\begin{array}{l}\text { - Apprehension of contractors to use high-volume replacements due to } \\
\text { unfamiliarity with finishing/placing requirements } \\
\text { - Potential for slower early strength gain } \\
\text { - Use of floor-specific codes as true indicators of overall performance of green } \\
\text { concrete }\end{array}$ \\
\hline $\begin{array}{l}\text { Low } \\
\text { Priority }\end{array}$ & $\begin{array}{l}\text { - Greater variability of green concretes compared to ordinary portland cement } \\
\text { (OPC) concretes } \\
\text { - Concerns about green concretes meeting requirements for strength and salt } \\
\text { scaling (i.e., flaking of a concrete surface that, when severe enough, may result } \\
\text { in lower skid resistance and reduced service life of the concrete) }\end{array}$ \\
\hline \multicolumn{2}{|c|}{ Performance Measures and Test Methods } \\
\hline $\begin{array}{l}\text { High } \\
\text { Priority }\end{array}$ & $\begin{array}{l}\text { - Insufficient durability test methods } \\
-\quad \text { Lack of sufficient test methods prevents acceptance } \\
\text { - } \quad \text { Lack of appropriate test methods for performance-based specifications } \\
\text { - Existing models and test methods must be modified for novel materials } \\
\text { - Validated computer models are useful for predicting durability; however, } \\
\text { they are not widely used and tests cannot be used as real-time QA/QC } \\
\text { checks for concrete } \\
-\quad \text { Lack of understanding of how to accelerate aging for any kind of concrete } \\
\text { - Existing test methods may not necessarily reflect field performance } \\
\text { - Acceptance of life cycle cost /total ownership cost for structures built for } 30 \\
\text { plus years of service versus initial cost } \\
\text { Reliance on old or superseded data, which limits replacement levels despite } \\
\text { better and larger body of knowledge supporting high replacement levels }\end{array}$ \\
\hline
\end{tabular}




\section{TABLE 3 1. BarRiers to THE EXPANDEd USE OF GREen CONCRETE}

\begin{tabular}{|c|c|}
\hline $\begin{array}{l}\text { Medium } \\
\text { Priority }\end{array}$ & $\begin{array}{l}\text { - Performance indicators for OPC concretes that may not be valid for high- } \\
\text { volume replacements } \\
\text { - Limited track record of proven long-term performance of novel green concrete }\end{array}$ \\
\hline $\begin{array}{l}\text { Low } \\
\text { Priority }\end{array}$ & $\begin{array}{l}\text { - Inadequate understanding of the link between fly ash composition and concrete } \\
\text { performance (i.e., performance predictors are needed) } \\
\text { - Continued use of a slump test (a long-established empirical quality control test } \\
\text { that may not be applicable without modification) inhibits acceptance of high- } \\
\text { volume SCMs } \\
\text { - Lack of a test method for deicer scaling that represents the actual performance } \\
\text { of high-volume SCMs } \\
\text { - Lack of robust test methods and proficiency testing programs to ensure } \\
\text { unbiased, reliable results that are accepted by the industry as credible for the } \\
\text { development of innovative new concretes } \\
\text { - Lack of real-time test data during concrete production (e.g., slump, } \\
\text { temperatures, calorimetry), as well as sufficiently qualified staff to make } \\
\text { adjustments }\end{array}$ \\
\hline
\end{tabular}

- Test data needs to be available for every batch of concrete; typically, once

- Inability to quickly determine the cause(s) of failures for new materials

\section{Characteristics of Replacement Materials}

\begin{tabular}{|c|c|}
\hline & $\begin{array}{l}\text { - Using new materials (that typically have slower strength gain) for fast track } \\
\text { construction that requires high early strength } \\
\text { - } \quad \text { High-percentage SCM mixtures are perceived to have low early strength } \\
\text { - } \quad \text { Some Class C fly ashes have dramatic detrimental effects regarding } \\
\text { acceleration or retarding concrete set times } \\
\text { - There is potential for unanticipated deleterious reactions } \\
\text { - } \quad \text { There is a wide misconception that Class F fly ash reduces strength and } \\
\text { - } \quad \text { Selays set time } \\
\text { - } \\
\text { Stigma remains } \\
\text { Early high strength is not always required; accelerators can sometimes be } \\
\text { - } \quad \text { High percentage of SCM mixtures that bleed water more slowly; however, } \\
\text { this can aid in finishing concrete with smaller crews }\end{array}$ \\
\hline $\begin{array}{l}\text { Medium } \\
\text { Priority }\end{array}$ & $\begin{array}{l}\text { - Poor controls on fly ash production, due to power utilities optimizing for power } \\
\text { output rather than fly ash quality, which can lead to variability of the source } \\
\text { material, even from the same power plant } \\
\text { - Lack of incentives for producers to generate uniform and predictable fly } \\
\text { ash due to the disconnect between suppliers and users } \\
\text { - Lack of tools to assess material selection options for optimal long-term } \\
\text { performance } \\
\text { - Inability to assess for compatibility in mixing, placing, and finishing } \\
\text { - Uncertainty in long-term performance for characteristics such as strength } \\
\text { - Lack of mineralogical characterization of IBP/SCM (e.g., fly ash); new } \\
\text { reference standards and materials are needed } \\
\text { - Characterization of phases (e.g., glassy vs. crystalline) }\end{array}$ \\
\hline
\end{tabular}




\section{TABLE 3 1. BarRiers to THE EXPANDEd USE OF GREen CONCRETE}

\begin{tabular}{|c|c|}
\hline $\begin{array}{l}\text { Low } \\
\text { Priority }\end{array}$ & $\begin{array}{l}\text { - Lack of knowledge of how IBPs will interact with portland cement; constituents } \\
\text { are optimized, rather than optimizing the system } \\
\text { - Lack of a sustainable, available supply of high-quality SCMs and other alternate } \\
\text { materials } \\
\text { - Insufficient supply of suitable material of uniform character } \\
\text { - Markets limit supply to a specific area or customer due to logistics } \\
\text { - Inability to produce materials in volume } \\
\text { - Inability to get competitive bid or a sole supplier }\end{array}$ \\
\hline \multicolumn{2}{|c|}{ Contracting Practices } \\
\hline $\begin{array}{l}\text { Medium } \\
\text { Priority }\end{array}$ & $\begin{array}{l}\text { - Lack of adequate contracting methods that enable green concretes to compete } \\
\text { with traditional concrete } \\
\text { - } \quad \text { Limited timeframe to qualify materials } \\
-\quad \text { Too many contracts that are overly complex and inflexible } \\
\text { - } \quad \text { Too many people involved (including the producer, pump operator, } \\
\text { finishing contractor, engineer, owner, prime contracts architect, } \\
\text { specification bodies) who all must agree to move forward } \\
\text { - Protecting proprietary data, and innovative research and development } \\
\text { (R\&D) } \\
\text { - Intellectual property issues involving research (i.e., right to publish) } \\
\text { Lack of clarity about who is responsible for performance or failure (a barrier } \\
\text { particularly relevant to a State DOT); uncertainty as to who assumes the risk } \\
\text { (owner, contractor, etc.) } \\
\text { - Incorrect information is often communicated post-failure, even when } \\
\text { - } \quad \text { Liaboans for failure and responsibility are understood }\end{array}$ \\
\hline $\begin{array}{l}\text { Low } \\
\text { Priority }\end{array}$ & $\begin{array}{l}\text { - Cost-effectiveness of SCMs } \\
-\quad \text { Lack of a plan for extra categories to accommodate IBP materials } \\
\text { - Lack of incentive to use greater than } 30 \% \text { portland cement replacement } \\
\text { materials } \\
\text { - Tendency to blame fly ash when systems fail }\end{array}$ \\
\hline \multicolumn{2}{|c|}{ Codes and Regulations } \\
\hline $\begin{array}{l}\text { Medium } \\
\text { Priority }\end{array}$ & $\begin{array}{l}\text { - Lack of regulations requiring a minimum level of SCMs } \\
\text { - Legacy or reclassification risk; i.e., the potential that fly ash may be classified } \\
\text { as a hazardous material } \\
\text { - Building code that restricts SCMs to a } 25 \% \text { limit in the presence of de-icing } \\
\text { chemicals which is based on aggressive lab tests that do not necessarily match } \\
\text { field performance } \\
\text { - Concern of engineers and specifiers about using over } 25 \% \text { as they are } \\
\text { unaware that the limit only applies to scaling (i.e., mass concrete uses are } \\
\text { commonly greater than } 25 \% \text { ) }\end{array}$ \\
\hline
\end{tabular}




\section{TABLE 3 1. BarRiers to THE EXPANDED USE OF GREen CONCRETE}

\begin{tabular}{l|l}
\hline \multirow{4}{*}{$\begin{array}{l}\text { Low } \\
\text { Priority }\end{array}$} & $\begin{array}{l}\text { Uncertainty in the requirements of U.S. Environmental Protection Agency } \\
\text { - }\end{array}$ \\
& $\begin{array}{l}\text { SPA) CCR Subtitle C } \\
\text { the ability of the producer to make changes to the mix design as materials } \\
\text { change } \\
\text { - Lack of capital investment and permitting for equipment for alternative cements } \\
\text { (e.g., silos, bins, and dispensing equipment in concrete plants) }\end{array}$ \\
\hline Education, Training, and Industry Culture
\end{tabular}

\footnotetext{
${ }^{\text {a }}$ Under the EPA Coal Combustion Residues (CCR) Subtitle C proposal, coal ash destined for beneficial use would retain the current Bevill exemption, and so would not be subject to regulation under Resource Conservation and Recovery Act Subtitle C. Thus, coal ash used in concrete and other products would not fall within the scope of EPA's proposal to "list" coal ash, either during or after the useful life of the concrete product. When the concrete product is discarded at the end of its useful life, it would be treated the same as any other solid waste. Source: http:/www.epa.gov/osw/nonhaz/industrial/special/fossil/ccr-rule/ccrfaq.htm
} 


\section{High Priority Topics}

For the most critical barriers identified in Table 3-1, small groups of two or three people worked together to enumerate the approaches and technical objectives to overcome them, along with recommended roles for stakeholders. These efforts resulted in the set of high priority challenge topic categories outlined below and detailed in Figures 3-1 through 3-6. Ideas from Group A and Group B were consolidated where necessary to eliminate overlaps.

Code and Specification Limitations: Building codes and some State Departments of Transportation (DOT) limit the use of SCMs. For example, in the ACI 318 building code, fly ash is limited to $25 \%$ of the total cementitious material when the concrete will be exposed to deicers. This limitation references publications that were published before 1990, and does not incorporate the significant amount of work that has been done in this field since. There is currently a test that can be used for scaling resistance and deicing salts that is considered a good predictor of performance in the field. Yet some evidence suggests that this test is overly restrictive and aggressive and can give false positives that would prevent the use of more SCMs. There is a need for measurement science to develop a better test or to validate tests for scaling resistance in the presence of deicer salts (see Figure 3-1). Similarly, State DOTs may limit the use of SCMs after a certain date in the year based on anecdotal evidence for set time or early age strength limitations. This conservative approach has been adopted due to a lack of reliable test methods and guides for accurately predicting potential problems. Education is also necessary to overcome this barrier; when SCMs are limited in one particular instance, it does not necessarily mean that the use of SCMs has to be limited in the rest of the project.

Life Cycle Tools and Sustainability Metrics: The lack of life cycle tools and sustainability metrics leads to limitations on being able to quantify the benefits and disadvantages of using different materials in concrete mixtures (see Figure 3-2). To overcome this barrier, it is necessary to be able to quantify sustainability, including service life, $\mathrm{CO}_{2}$ footprint, embodied energy, and environmental costs and benefits. For each of these quantities, it is important to consider not just one stage of the material use, but all stages, including building, operation, and disposal (including the possibility for recycling the material again). For example, embodied energy must include the initial energy to build a particular project and the energy required for operation. The successful creation of sustainability metrics relies on the development and validation of new service life tools and performance prediction models that can incorporate the multiple degradation mechanisms that pertain to a particular application.

Predictive Performance Models: Reliable models that can accurately predict the performance of IBP concrete mixtures, both during construction and over the long- 
term, must be developed and validated to build confidence in the mixtures. The development of these models will involve multiple iterative steps: develop a systematic approach for evaluating IBPs in concrete mixtures, develop the actual model, and then validate the model (see Figure 3-3). It is preferable that these performance models be based on materials science principles, but should not be overly restrictive. Current OPC concrete is based primarily on empirical data. In order to predict concrete performance based on IBP characteristics, the interaction of IBPs with other components of the concrete mixture must be well understood. Outreach and/or education will likely be necessary for the standards community to accept and be confident in these new performance models. Finally, there is a need for improved test methods that will yield data as inputs to these models.

Improved Test Methods: The reluctance of industry to use high-volume replacement concretes is primarily based on the uncertainty and unfamiliarity with IBP materials. Test methods that are understandable to technicians/lay engineers, practical, and cost effective should be developed, and the repeatability and reproducibility of those test methods must be understood (see Figure 3-4).

Materials Characterization Tests: The current practice of characterizing IBP materials by their oxide content is insufficient for understanding whether a concrete mixture made with a particular IBP material will perform as intended. Current tests based on a pozzolanic (strength activity) index are not reliable for mixtures with large SCM replacements. New standard test methods and certified reference materials should be developed for materials such as fly ash, glasses, and minerals that give a better indication of performance, such as the proportion of glassy and crystalline material or calorimetry data for mixtures of controlled proportions (see Figure 3-5). The development of blended binder materials also requires the quantification of various material properties such as component content and component composition. Knowing what property to measure, however, depends upon having a sufficient understanding of the processes involved.

Understanding of Hydration Reactions: A central barrier, and one that relates to many of the technical challenges already noted, is the lack of a fundamental understanding of the reactions that occur during the hydration process in concretes made with IBP materials. The IBP materials are largely glassy (amorphous structure), and these glass reactions are not fully understood, particularly in the presence of portland cement. From the field of cement chemistry, it is known that proper sulfate balancing is needed to achieve desirable properties during construction. From the field of glass chemistry, researchers have an inherent understanding that alkalis and alumina phases play important roles, especially as the portland cement replacement moves beyond $50 \%$. There is also evidence that fine limestone powder can be used to engineer setting time, even in the absence of 
evidence that the limestone is reacting chemically. ${ }^{\mathrm{b}}$ Activities addressing this challenge are woven into several of the priority topics described.

Stakeholder Education and Awareness: The construction industry, which is risk averse by nature, has a strong preference for using traditional methods and technologies, posing a challenge for introducing the innovative technologies that are common in green concrete (see Figure 3-6). There is currently a significant lack of understanding regarding new concrete materials, especially regarding benefits, costs, risks, and characteristics such as strength and durability. During construction, these materials can behave differently from OPC concretes, especially with respect to bleeding and the appropriate finishing plan, and contractors need reliable tests and tools to ensure the best possible product. Training, tutorials, showcases, and life cycle analysis tools are all necessary for the construction industry to learn how to work with SCMs.

${ }^{\mathrm{b}}$ See for example: Gurney, L., Bentz, D.P., Sato, T., and Weiss, W.J., Using Limestone to Reduce Set Retardation in High Volume Fly Ash Mixtures: Improving Constructability for Sustainability, 


\section{Figure 3-1. Code and Specification Limitations:} Effects of High-Volume SCMs on Concrete Properties Impacting Constructability

TECHNICAL OBJECTIVE: Improve predictive tests and strategies to mitigate the adverse effects of high-volume supplementary cementitious material (SCMs) on concrete



What new technologies or information/data are needed to overcome this challenge/barrier?

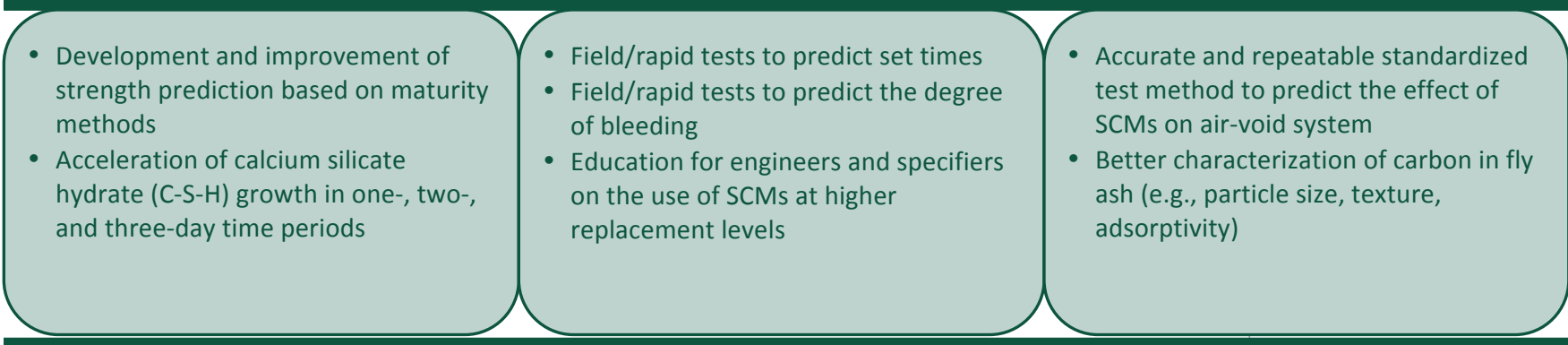

What measurement science solutions are needed to implement each new technology or data?

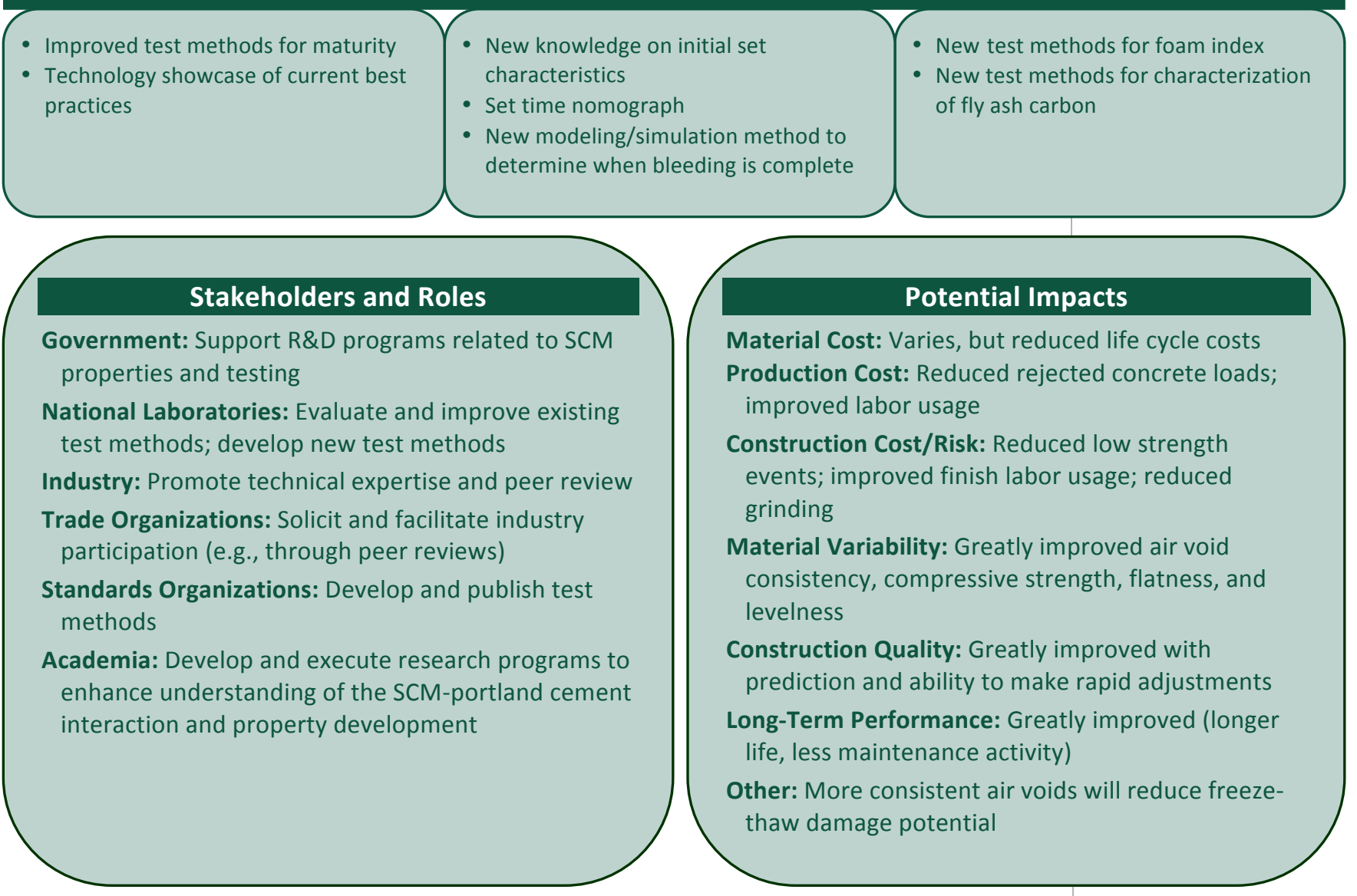




\section{Figure 3-2. Life CyCle Tools and Sustainability Metrics: Life Cycle and Sustainability Analysis for Green Concretes}

TECHNICAL OBJECTIVE: Quantify sustainability for properties such as service life, carbon dioxide $\left(\mathrm{CO}_{2}\right)$ footprint, embodied energy, and environmental costs and benefits


What new technologies or information/data are needed to overcome this challenge/barrier?

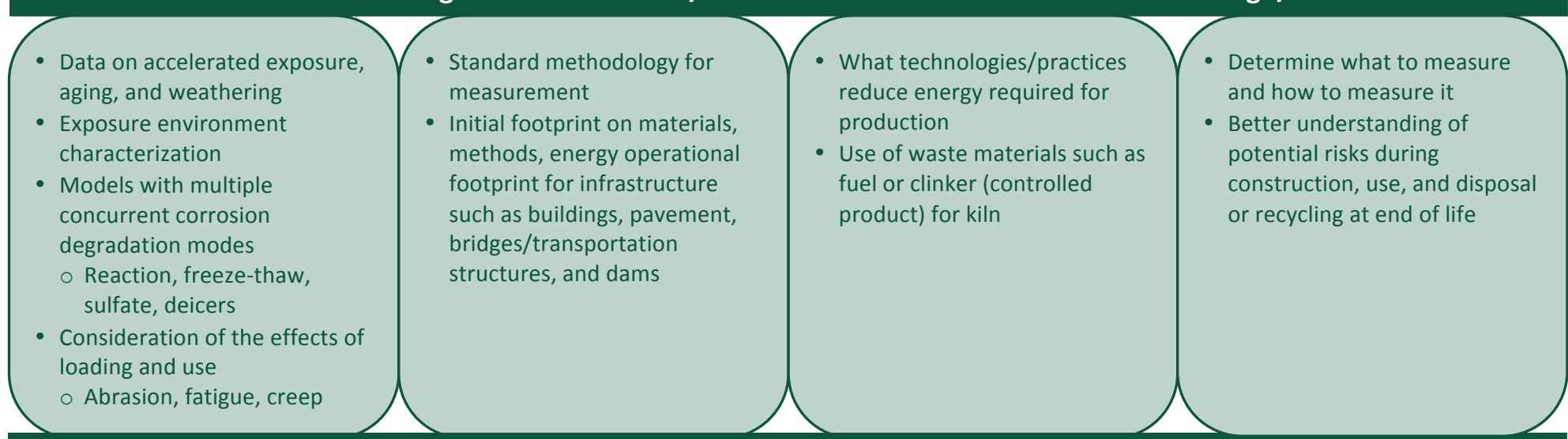

\section{What measurement science solutions are needed to implement each new technology or data?}






\section{Figure 3-3. Predictive Performance Models:}

Reliable Predictive Models for Concrete Mixtures Containing IBPs

\section{TECHNICAL OBJECTIVE: Develop and validate reliable predictive performance models}

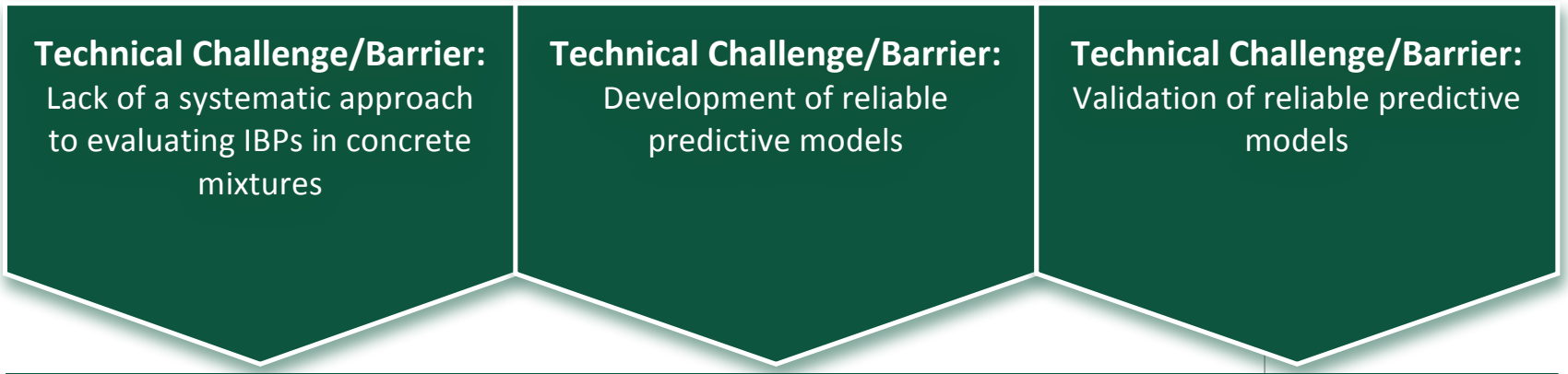

What new technologies or information/data are needed to overcome this challenge/barrier?

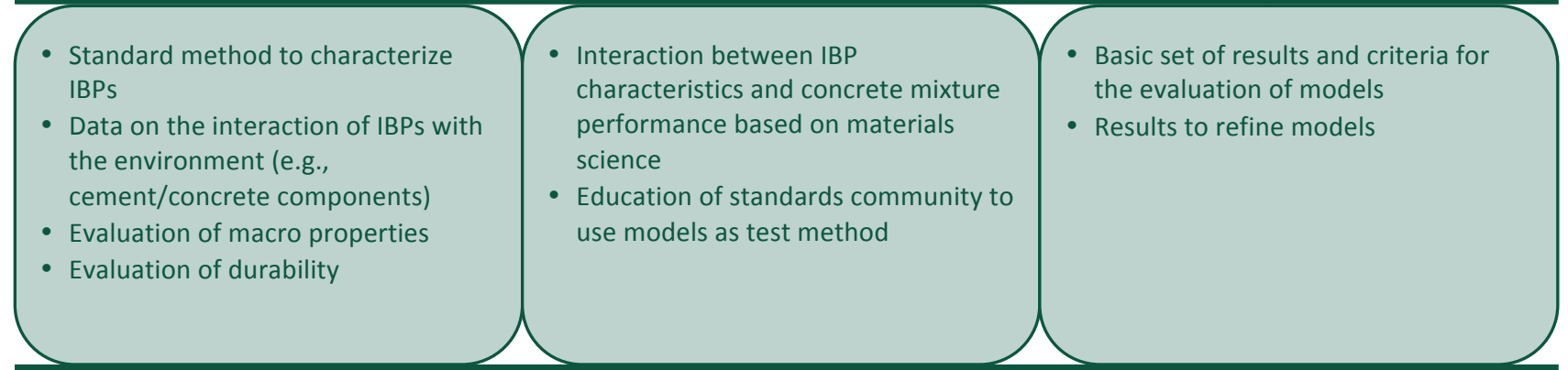

What measurement science solutions are needed to implement each new technology or data?

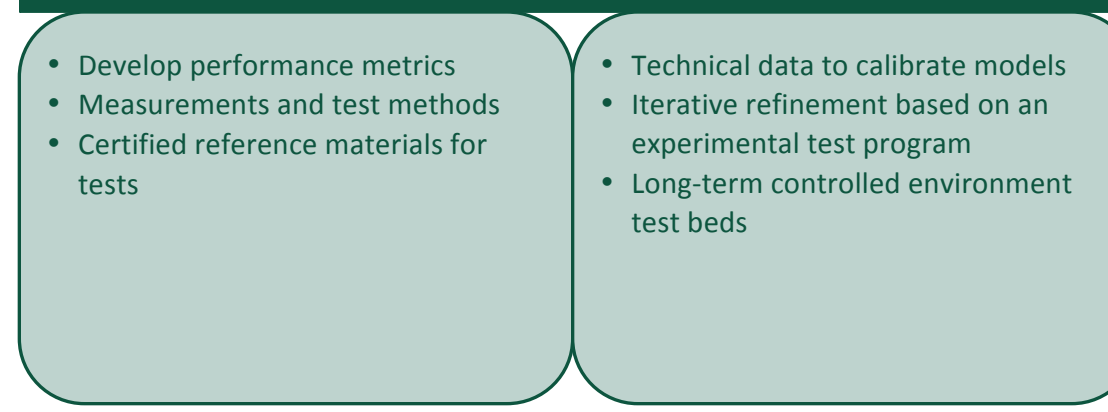

\section{Stakeholders and Roles}

Government: Conduct long-term exposure tests beds

National Laboratories: Create long-term exposure test bed reference materials; fundamental material science research

Industry: Develop data for material characterization

Trade Organizations: Provide source of IBPS

Standards Organizations: Standardize models and incorporate into specifications

Academia: Educate about methods, models, and fundamental materials science
- Certified reference materials

- Technical data to input into models and validate outputs

- Long-term exposure site

\section{Potential Impacts}

Material Cost: No impact

Production Cost: Reduced; able to use cheaper IBPS Construction Cost/Risk: Reduced risk; more reliable performance

Material Variability: Will still exist (but performance will be better predicted)

Construction Quality: Improved

Long-Term Performance: Improved

Other: N/A 


\section{TECHNICAL OBJECTIVE: Develop more reliable performance test methods (durability, aging, field performance)}
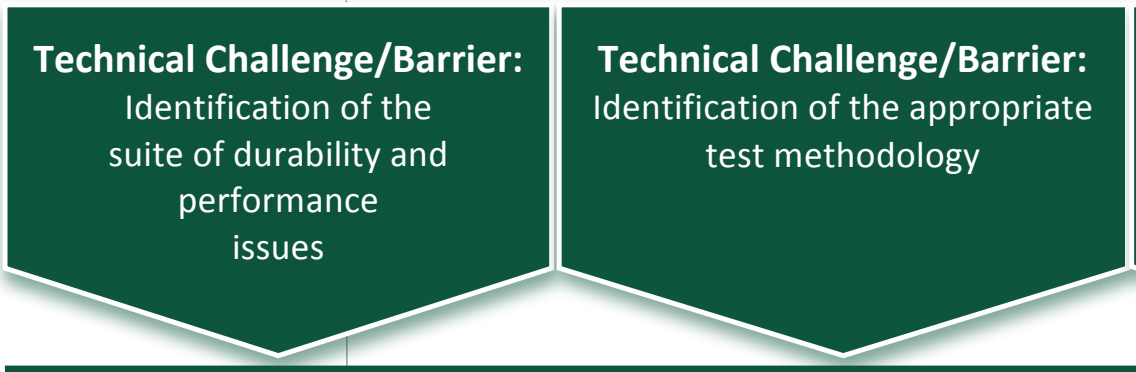

\section{Technical Challenge/Barrier:}

Development of reliable, trusted

test methods and predictive

models (when appropriate) for

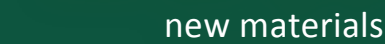

\section{What new technologies or information/data are needed to overcome this challenge/barrier?}

$\left.\begin{array}{l}\text { - Industry survey for data of durability } \\ \text { issues } \\ \text { - Definition of boundary of } \\ \text { applicability to materials such as } \\ \text { geopolymers, belite }\left(\mathrm{C}_{2} \mathrm{~S}\right) \text { cements } \\ \text { and other cementitious systems }\end{array}\right)\left(\begin{array}{l}\text { - Ability to determine whether a } \\ \text { particular test is appropriate to the } \\ \text { material } \\ 0 \text { i.e., early testing on high volume } \\ \text { fly ash concrete } \\ \text { Basic understanding of new } \\ \text { materials } \\ \text { i.e., microstructure chemistry, } \\ \text { phase changes of geopolymers }\end{array}\right)\left(\begin{array}{l}\text { Direct, proxy, virtual, and laboratory } \\ \text { tests } \\ \text { Tests for accurate prediction of } \\ \text { durability and field performance } \\ \text { Reliable prediction of long-term } \\ \text { performance (accelerated aging) } \\ \text { Durability data on freeze-thaw, } \\ \text { deicing, carbonation, environmental, } \\ \text { and alkali-silica reaction (ASR) gels }\end{array}\right)$

\section{What measurement science solutions are needed to implement each new technology or data?}

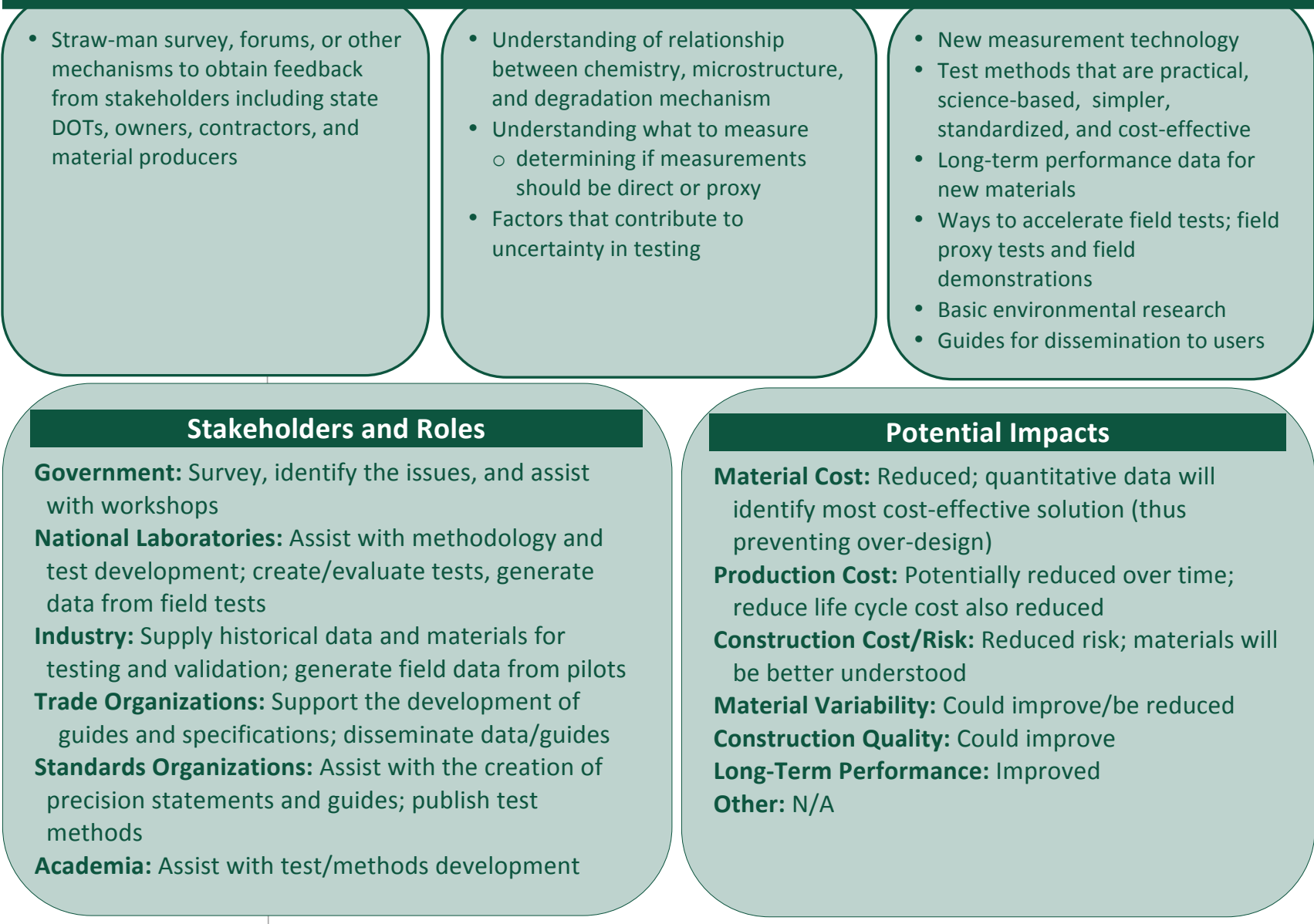


Figure 3-5. Materials Characterization Tests Methods and Reference Materials for Fly Ash, Glass, and Minerals

TECHNICAL OBJECTIVE: Develop methods and reference materials for concrete replacement materials such as fly ash, glass, and minerals

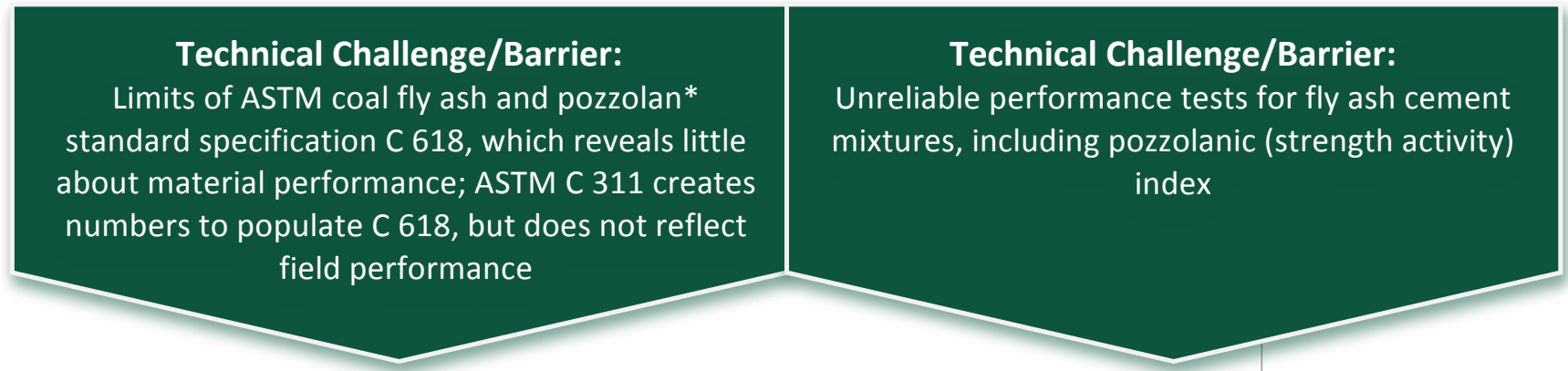

What new technologies or information/data are needed to overcome this challenge/barrier?

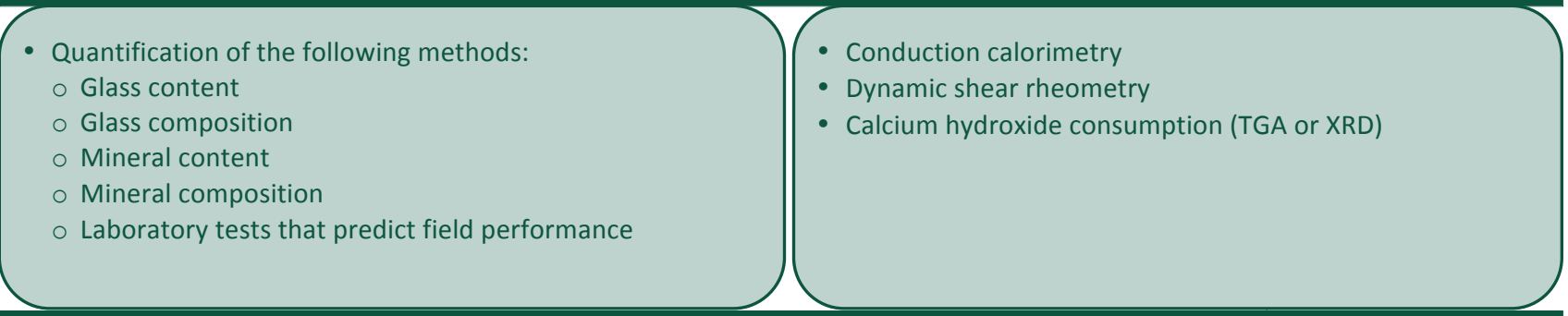

\section{What measurement science solutions are needed to implement each new technology or data?}

- Standard test methods for fly ash, glass, and minerals

- Reference materials for fly ash, glass, and particle size distribution

- Performance-based test for Class C fly ash ASR evaluations
- Standard test protocols for mixtures

- Standard reaction model

- Reference materials to support test methods

- Improved test methods for scaling resistance in the presence of deicer salts

\section{Stakeholders and Roles}

Government: Identify opportunities for demonstration projects

National Laboratories: Develop reference data and conduct precision statement studies

Industry: Provide historical data; supply materials to researchers

Trade Organizations: Develop guides and draft standards and codes

Standards Organizations: Develop new test methods and codes

Academia: Develop new characterization techniques

\section{Potential Impacts}

Material Cost: N/A

Production Cost: Fewer overtime days

Construction Cost/Risk: Reduced uncertainty in scheduling

Material Variability: Unanticipated delayed set times are avoided

Construction Quality: N/A

Long-Term Performance: N/A

Other: N/A

* Pozzolan refers to class of siliceous or siliceous and aluminous materials which possess little or no cementitious value independently but which will, in finely divided form and in the presence of water, react chemically with calcium hydroxide at ambient temperature to form compounds that have cementitious properties (ASTM C618). 
Figure 3-6. STAKeholder EduCation AND AWAREness: Educating Industry and the Public about Working with SCMs and the Benefits

TECHNICAL OBJECTIVE: Educate the industry on how to work with SCMs; build confidence in the use of new materials; and educate stakeholders and the public about their benefits

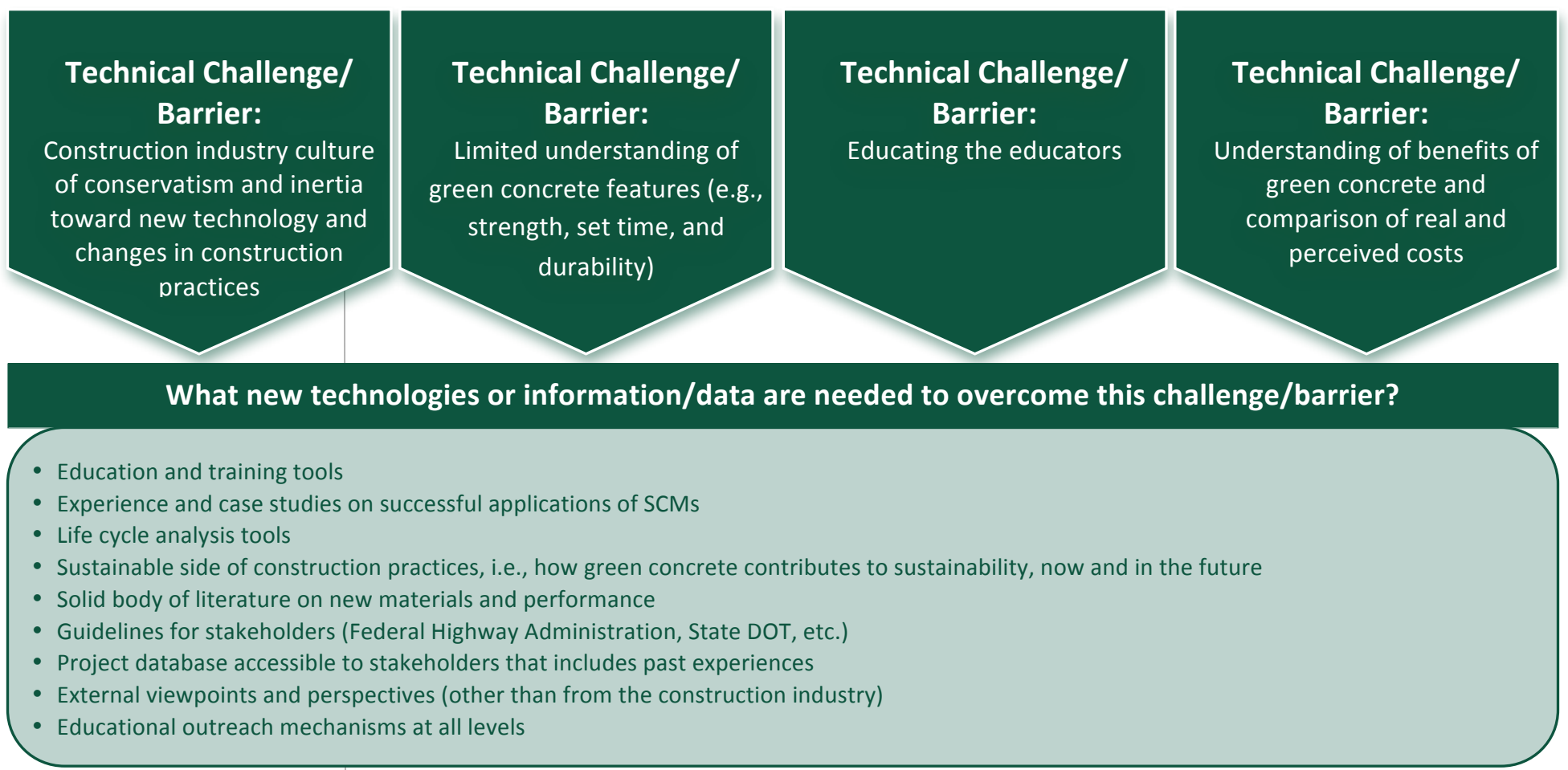

\section{What measurement science solutions are needed to implement each new technology or data?}

- Technical data and reference materials

- Feedback loop that will help to verify that the new information or data has arrived (absorbed) - (ACl training courses)

- Metrics that measure benefits in a transparent and understandable way

- Methods and data to aid in understanding the behavior and properties of SCMs

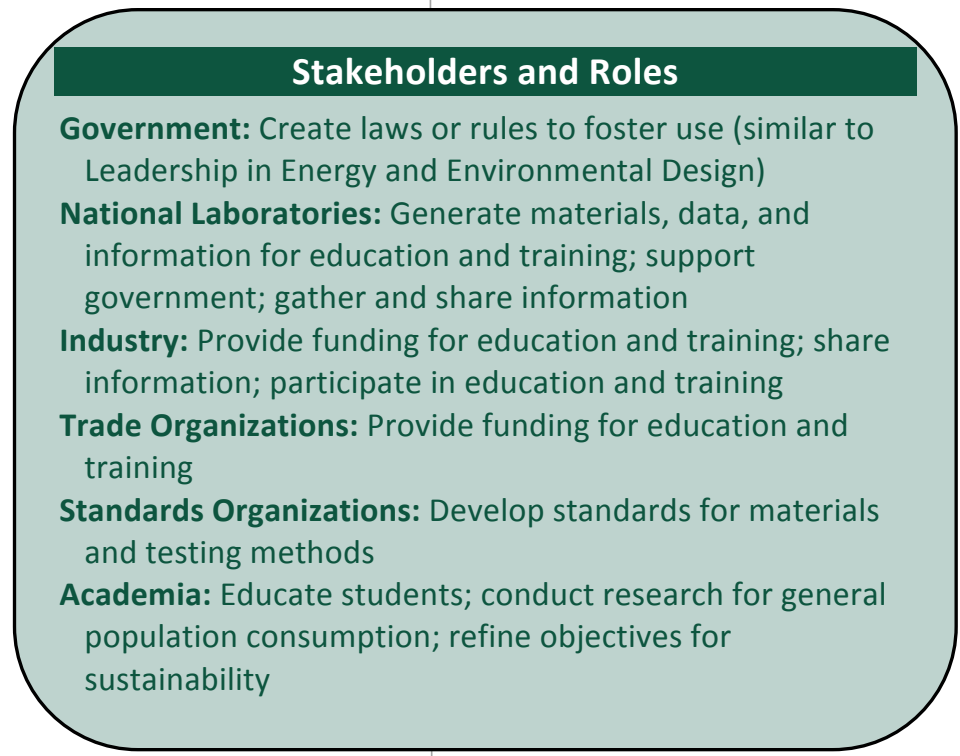

\section{Potential Impacts}

Material Cost: Will depend on the cost/benefit ratio-each material is different

Production Cost: Will depend on successful case studies and past experience

Construction Cost/Risk: Will depend on successful case studies and past experience

Material Variability: Educated/experienced work force will help guarantee success

Construction Quality: Educated/experienced work force will help guarantee success

Long-Term Performance: Educated/experienced work force will help guarantee success

Other: Quality of life has potential for greater improvement; sustainability issues are of growing importance 


\section{A MEASUREMENT SCIENCE ROADMAP}

New measurement science is needed to support progress in the High Priority Topic areas discussed previously. These needs include a number of measurement science areas: new understanding as a basis for new measurement technologies and methods; new standardized tests to support changes in specifications and codes; and new industry best practice guides to support educational programs.

The following is a brief summary of the needs that are aligned with the High Priority Topic areas. Although the list below does not span all of the technical needs identified in this report, they contribute directly or indirectly to the topic areas identified. Moreover, it is hoped that this summary can form the basis of future collaborations, both nationally and internationally.

\section{Materials Characterization Test Methods}

One of the overwhelming challenges to working with IBP materials is adapting to variability in the properties of these materials. The challenge is two-fold:

understand what parts of the glassy phases have the greatest impact on performance; and develop test methods to address known complexity (crystalline and heterogeneous glassy composition). The first challenge is very broad and will require collaboration among multiple contributors. In the short term, there are a number of known important characteristics for which there are no standardized test methods. For example, having a test method to identify and quantify the crystalline phases in a fly ash would allow one to determine, by subtraction, the average oxide composition of the glassy phases present.

- Develop collaborations among researchers to understand the chemical and physical reactions that occur when IBP materials react in an alkaline solution

- Identify critical characteristic of IBP materials that impact performance during construction and over the long-term.

- Evaluate the use of ASTM C188 for determining the densities of IBP materials

- Develop reference materials for glassy materials to aid in calibration of devices 
- Develop a standard test method for chemical (oxide) analysis of IBP materials

- Develop a standard test method for identifying and quantifying the crystalline phases present in mixed (glassy and crystalline) IBP materials like fly ash.

- Develop a reference material that would replicate both the chemistry and the mineralogy of IBP materials

\section{Performance-Based Test Methods}

A majority of the existing standardized test methods were developed based on the characteristics of ordinary portland. For example, a number of durability tests begin exposure after 14 days of hydration, whereas concretes with increasing cement replacement levels hydrate more slowly. Even during construction, the (often) finer particle sizes of IBP materials can reduce bleed rates to the rate of water evaporation, thus confounding the expectation of the ideal time to finish the surface. Existing test methods should be re-evaluated to identify the factors that contribute to a performance failure, and identify improvements to the test methods that will ensure that the performance of a concrete mixture is characterized accurately.

- Develop test methods that can more accurately indicate the ideal finishing time for concrete mixtures containing elevated replacement levels of IBP materials.

- Develop standardized test methods for reporting the temperature dependence of setting time and strength of a concrete mixture

- Develop a standardized test that accurately reflects the scaling performance of HVFA concrete mixtures

- Develop test methods that can accurately reflect the long-term performance of concrete mixtures containing elevated portland cement replacement levels; this may involve developing accelerated test methods

\section{Best Practice Guides and Codes}

Improved industry best practice guides could form a foundation for improved industry-wide performance, and for informing the industry that concretes with elevated portland cement replacement levels can be constructed reliably, and can be expected to perform for the intended service life.

- Work with the ACI-relevant committees to develop alternative mixture design guidelines, including volumetric proportioning options (such as the aggregate suspension mixture proportioning method currently under development within ACI 211)

- Develop guides for selecting concrete mixture designs based on the temperature dependence of setting time and early age strength. 
- Develop guides for developing and qualifying innovative mixture proportioning for green concretes such as HVFA ternary blends consisting of fine limestone powder, ordinary portland cement, and (coarse) fly ash

- Work with ACI Committee 318 to more accurately reflect the conditions under which concrete mixtures with elevated portland cement replacement levels can/cannot perform satisfactorily 


\section{APPENDIX A. SUCCESSFUL EXAMPLES OF GREEN CONCRETE}

While a number of challenges exist to using replacement concrete materials, many real world successes using green concrete have been documented (HighPerformance, High-Volume Fly Ash Concrete, V.M. Malhotra and P.K. Mehta, 2012). The Unified Facilities Guide Specifications (UFGS) now provides guidance allowing marine concrete projects for the Navy, Army, Air Force and NASA to use performance-based green concrete mixtures based on over 7 years of experience on large concrete projects with a specified service life. The use of supplemental cementitious materials, such as fly ash, is encouraged. For example, Class F fly ash may be used up to $50 \%$ as a partial replacement for Portland cement. By definition, a concrete mixture containing a minimum of $50 \%$ fly ash is defined as a high-volume fly ash (HVFA) concrete (Malhotra \& Mehta, 2012). The use of green concrete in structures offers numerous direct and indirect benefits including lifecycle cost savings, extended service life, little or no cracking, reduced greenhouse gas emissions by displacing portland cement, and reduced energy consumption.

\section{U.S. Navy Use of Green Concrete}

The U.S. Navy's Naval Facilities Engineering Command (NAVFAC) has been a leader in developing and using performance specifications and green concrete mixtures on large projects since 2005 , when they utilized $40 \%$ fly ash in a modular hybrid pier test structure at San Diego, CA. Performance specifications, characterization of green concrete mixtures, and the use of service modeling tools, have been developed and validated by the U.S. Navy. There are already examples of demonstrations that support the feasibility and constructability of using greener, cheaper, and more corrosion-resistant concrete mixtures for use in Navy structures.

As expected, the Navy has use for green concretes that can be used in waterfront projects. A pier at Naval Base Kitsap in Bremerton, WA involved the use of a concrete mixture containing $15 \%$ fly ash and $7.5 \%$ silica fume. However, higher fly ash composition concrete mixtures are also being explored. Three test beams were designed and fabricated to represent a reinforced concrete pile cap for a Navy pier. Two of the beams were made from HVFA concrete with 50\% fly ash and one 
control beam was made from traditional concrete. During the production of the beams, slump tests were satisfactory and the concrete showed good consolidation and finished well. After being sent to a waterfront test site, the beams have shown no cracks so far.

As another example, a contractor for the Navy completed the construction of a biofuel containment slab at a biodiesel plant located at the National

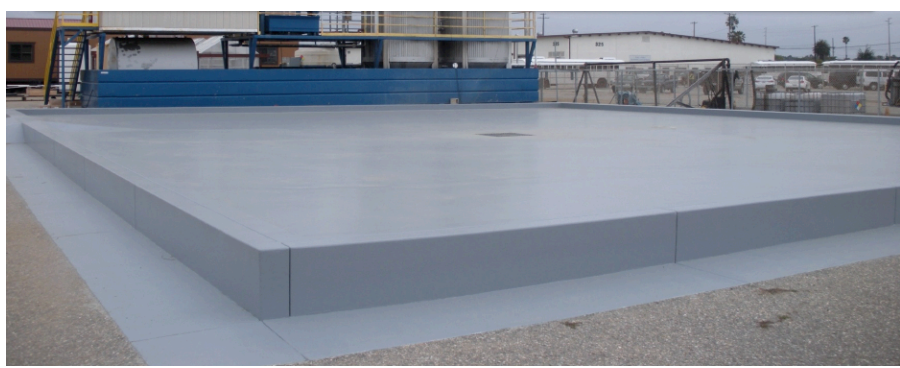

HVFA concrete biofuel containment slab at a biodiesel plant in Port Hueneme. CA

Environmental Test Site at Naval Base Ventura County in Port Hueneme, CA. This slab was constructed using HVFA concrete which contained 50\% fly ash and 50\% cement. Compared to conventional concrete mixtures, the contractor noted that it was easier to patch curbs when using the HVFA concrete. Other benefits were seen by using the green concrete including that there was less cracking and it was easier to create a flat finish. The labor cost of the construction project was reduced by $15 \%$ and the crew was able to have a longer set-up time. Also, the cost of the HVFA concrete was the same as that which would come from a ready mix supplier. The use of green concrete was so successful for this project that the contractor noted that this material is preferred for all their future Navy projects and will possibly be used for commercial construction projects.

\section{Green Concrete in Construction Projects at the University of California, Berkeley}

A number of noteworthy construction projects have been completed utilizing green concrete in and around the San Francisco Bay Area, especially at the University of California, Berkeley (UCB). In 2012, UCB completed a seismic retrofitting and renovation of the University of California, Berkeley

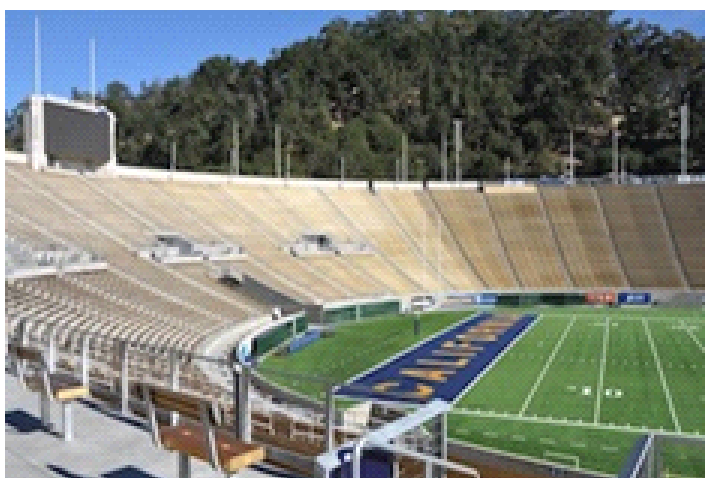

University of California, Berkeley Memorial Stadium

Memorial Stadium in 2012

The Memorial Stadium was a major construction project and utilized over 50,000 cubic yards of concrete. Portions of the stadium, including the mat foundations, footings, grade beams, columns, shear walls, and pile caps, were constructed using HVFA concrete which contained 50-55\% fly ash in place of portland cement. Although the floor and roof slabs utilized conventional concrete due to concerns by 
the contractor that strength gain would be too slow, HVFA concrete could have successfully been used without delaying the project. In October 2012, there were no cracks larger than 0.006 inches wide for all of the elements that were constructed using HVFA concrete, showing a successful implementation of the green concrete. In contrast, typical cracks in the roof and decks which were not made of HVFA concrete showed cracks in excess of 0.02 inches.

In 2001, UCB completed a seismic rehabilitation of Barker Hall. The material used was also HVFA concrete, where $50 \%$ of the portland cement was replaced with fly ash. Using green concrete to complete the building's rehabilitation avoided the emissions of 1300 tons of carbon emissions and

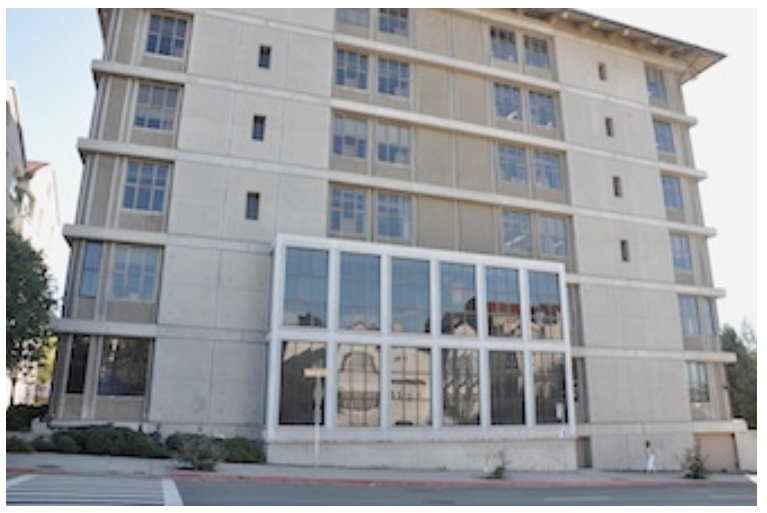

University of California, Berkeley Barker Hall the use of 1300 tons of portland cement. Eleven years after completion, the largest crack found was 0.007 inches wide which is within acceptable limits.

UCB has completed other construction projects using green concrete in the last 11 years in addition to the Memorial Stadium and Barker Hall. These notable projects include the seismic retrofit of Wurster Hall in 2001 and construction of the building headquarters of the Center of Information Technology Research in the Interest of Society (CITRIS) in 2007.

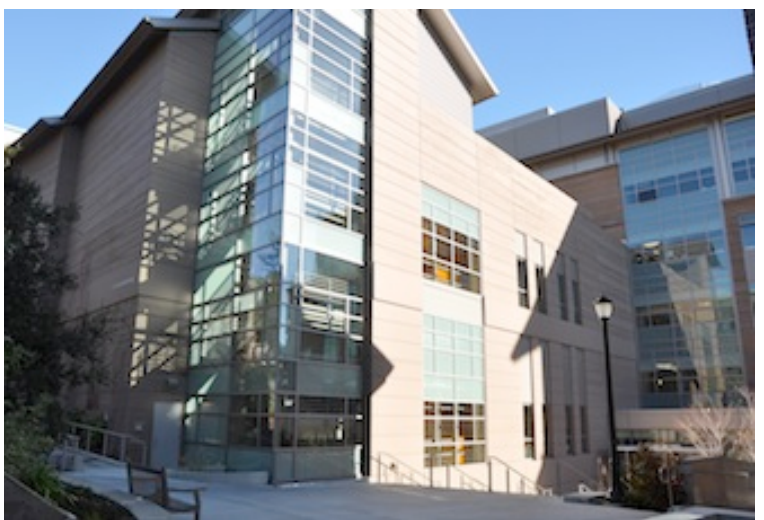

University of California, Berkeley CITRIS Building The CITRIS building used the same concrete mix as was used for the rehabilitation of Barker Hall, and five years after construction, there were no cracks found in the exterior of the walls. 


\section{APPENDIX B: ACRONYMS}

ACI

ASR

ASTM

$\mathrm{CO}_{2}$

DOT

EPA

GHG

HVFA

IBP

LCA

NIST

OPC

R\&D

SCM

SRM ${ }^{\circledR}$
American Concrete Institute

alkali-silica reaction

American Society for Testing and Materials

carbon dioxide

Department of Transportation

U.S. Environmental Protection Agency

greenhouse gas

high volume fly ash

industrial by-product

life-cycle analysis

National Institute of Standards and Technology

ordinary portland cement

research and development

supplementary cementitious material

Standard Reference Material 


\section{APPENDIX C: REFERENCES}

${ }^{1}$ Portland Cement Association, "Cement \& Concrete Basics - Concrete Basics," Accessed October 2, 2012, www.cement.org/basics/concretebasics concretebasics.asp.

${ }^{2}$ William T. Choate, Energy and Emission Reduction Opportunities for the Cement Industry, prepared by BCS, Incorporated, Columbia, MD (Washington, DC: U.S. Department of Energy, 2003), www1.eere.energy.gov/manufacturing/industries technologies/imf/pdfs/eeroci dec03a.pdf.

${ }^{3}$ Energy Information Administration, "Energy in Brief: How Can We Compare or Add up Our Energy Consumption?" (Washington, DC: U.S. Department of Energy, March 12, 2009),

www.greatlakesenergyservice.org/documents/comparing_energy_consumption.pdf.

${ }^{4}$ Energy Information Administration, Annual Energy Review 2008, DOE/EIA0384(2008) (Washington, DC: U.S. Department of Energy, 2009), www.eia.gov/totalenergy/data/annual/archive/038408.pdf.

${ }^{5}$ Energy Information Administration, Annual Energy Outlook 2009, DOE/EIA0383(2009) (Washington, DC: U.S. Department of Energy, 2009), www.eia.gov/oiaf/aeo/pdf/0383(2009).pdf.

${ }^{6}$ Energy Information Administration, Emissions of Greenhouse Gases in the United States 2007, DOE/EIA-0573(2007) (Washington, DC: U.S. Department of Energy, 2008), www.eia.gov/oiaf/1605/ggrpt/pdf/0573(2007).pdf.

${ }^{7}$ Hendrik G. Van Oss, 2007 Minerals Yearbook: Cement [advanced Release] (Reston, VA: U.S. Geological Survey, 2009), http://minerals.usgs.gov/minerals/pubs/commodity/cement/myb1-2007-cemen.pdf.

${ }^{8}$ International Energy Agency, Tracking Industrial Energy Efficiency and CO2 Emissions (Paris: International Energy Agency, 2007), www.iea.org/textbase/nppdf/free/2007/tracking_emissions.pdf.

${ }^{9}$ Peter Edwards, "Cement in the USA," Global Cement, May 14, 2012. www.globalcement.com/magazine/articles/698-cement-in-the-usa.

${ }^{10}$ Ed Sullivan, "Cement Outlook," (presentation, Portland Cement Association Spring Meeting, April 2012), www.ficem.org/boletines/informa/pca junio 2012/boardspring 20124 PCA.pdf.

${ }^{11}$ Environmental Protection Agency, "Frequent Questions: Coal Combustion Residues (CCR) - Proposed Rule," Environmental Protection Agency, accessed October 2, 2012, www.epa.gov/osw/nonhaz/industrial/special/fossil/ccr-rule/ccrfaq.htm 